\title{
Mechanisms of joint and microstructure formation in high power ultrasonic spot welding 6111 aluminium automotive sheet
}

\author{
D. Bakavos, P.B. Prangnell* \\ Materials Science Centre, School of Materials, The University of Manchester, Grosvenor Street, Manchester M1 7HS, UK
}

\section{A R T I C L E I N F O}

\section{Article history:}

Received 10 March 2010

Received in revised form 11 June 2010

Accepted 14 June 2010

\section{Keywords:}

Ultrasonic welding

AA6111

Aluminium

Microbonding

Tomography

Flow features

Lap shear strength

\begin{abstract}
A B S T R A C T
Resistance spot welding (RSW) is difficult to apply to aluminium automotive alloys. High power ultrasonic spot welding (HP-USW) is a new alternative method which is extremely efficient, using $\sim 2 \%$ of the energy of RSW. However, to date there have been few studies of the mechanisms of bond formation and the material interactions that take place with this process. Here, we report on a detailed investigation where we have used X-ray tomography, high resolution SEM, and EBSD, and dissimilar alloy welds, to track the interface position and characterise the stages of weld formation, and microstructure evolution, as a function of welding energy. Under optimum conditions high quality welds are produced, showing few defects. Welding proceeds by the development and spread of microwelds, until extensive plastic deformation occurs within the weld zone, where the temperature reaches $\sim 380^{\circ} \mathrm{C}$. The origin of the weld interface 'flow features' characteristic of HP-USW are discussed.
\end{abstract}

(C) 2010 Elsevier B.V. All rights reserved.

\section{Introduction}

The pressures of climate change are driving the automotive industry towards more fuel efficient products and lower energy consumption manufacturing processes. In the future this will require the greater use of lightweight body structures fabricated from aluminium and magnesium alloys, as well as multi-material designs [1]. This 'road map' for the industry has highlighted the need for more efficient joining methods. Because it is a cheap and robust process, steel car bodies are conventionally joined by electrical resistance spot welding (RSW). Unfortunately, RSW is difficult and expensive to apply to aluminium alloys, owing to their high conductivity, low strength at temperature, and tendency to degrade the electrodes $[2,3]$. Of particular concern is the high energy cost of resistance spot welding aluminium (see Table 1) with $50-100 \mathrm{~kJ}$ required per weld [4,5]. Alternative solutions are self-piercing rivets, clinching, friction stir spot welding (FSSW), adhesive bonding, laser welding and GTAW, or GMAW [6-8]. However, fusion processes are limited by the poor weldability and high levels of distortion that are characteristic of aluminium alloys [6]; further, riveting and bonding have additional consumable and surface treatment costs, respectively [7]. FSSW is an interesting more

\footnotetext{
* Corresponding author. Tel.: +44 161306 3610; +44 1613063586. E-mail addresses: dimitrios.bakavos@manchester.ac.uk (D. Bakavos), philip.prangnell@manchester.ac.uk (P.B. Prangnell).
}

efficient ( $\sim 3-6 \mathrm{~kJ}$ per weld) solid-state process which shows considerable potential for joining aluminium and dissimilar materials [8-11]. Under optimum conditions the joint's mechanical performance are comparable to RSW, but the weld cycle can be quite long (e.g. 2-5 s [7-10,12,13]).

A further spot joining process that has received less attention is ultrasonic welding (USW) [4,5,14-17]. Although ultrasonic welding has been used since the 1950s to join thin foils [18], it has only comparatively recently become economic to apply this technique to thicker gauges, due to the wider availability of higher power systems. USW is an attractive point joining technique for light alloys, as it is far more efficient than RSW, using only $0.6-1.5 \mathrm{~kJ}$ per weld. It is also more efficient than FSSW, because the energy is predominantly generated at the weld-line $[19,20]$ rather than at the top surface $[8,9]$. Furthermore, USW has the same advantages as FSSW, in that it is a solid-state friction joining process, but has a shorter weld cycle (typically<0.5 s), and has been reported to form joints with good mechanical performance and no HAZ damage $[4,14,15]$. Recently the Ford Motor Company have investigated the feasibility of applying ultrasonic welding (USW) to spot welding aluminium body structures with promising results $[4,5,17]$.

An ultrasonic metal spot welder typically consists of five main elements (Fig. 1): (i) The power supply, which provides electrical energy at a high frequency (typically $20 \mathrm{kHz}$ ), (ii) a piezoelectric transducer, which converts electrical energy into linear mechanical vibrations of the same frequency, (iii) a wedge that amplifies the mechanical amplitude, (iv) a reed, which transmits vibratory 
Table 1

Comparison of the approximate energy requirements and weld cycle times for different spot joining processes in $1 \mathrm{~mm}$ aluminium sheet.

\begin{tabular}{lcc}
\hline Process & Energy per weld $(\mathrm{kJ})$ & Weld time $(\mathrm{s})$ \\
\hline RSW & $50-100$ & $0.15-0.3$ \\
FSSW & $3-6$ & $1-5$ \\
USW & $0.6-1.5$ & $0.25-0.6$ \\
\hline
\end{tabular}

energy to the work piece and, finally, (v) a pneumatic cylinder, that provides a clamping pressure during welding. The operating power of sheet metal spot welders, under consideration for automotive applications, is of the order of $2-3 \mathrm{~kW}$ [4]. In a dual reed welder two sonotrode tips couple with both outside surfaces of the lapped sheets, and oscillate out of phase, which introduces a small ( 20-40 $\mu \mathrm{m}[21]$ ) high frequency linear displacement across the weld interface under a normal load resulting from the clamping force.

While much research has been carried out on ultrasonic welding of thin foils and wires within the electronics industry (e.g. $[18,21-24])$, there has been surprisingly few in depth investigations into the weld evolution and material interactions with this technique. Most research on conventional low energy USW assumes bonding occurs at relatively low temperatures $\left(<300^{\circ} \mathrm{C}\right)$ and is dominated by contact mechanics, with any deformation highly localised to the weld faying surfaces [18,21,24-26]. It is thought that sliding across the interface breaks the oxide between the two surfaces at contacting asperities resulting in adhesion, forming microwelds, which then increase in density and spread over the area affected by the vibration of the sonotroded tips. The weld strength is thus primarily related to the effective net area of microbonds [26]. Heat is generated initially from sliding friction, and the anelastic response of the material, but as galling and microbonds form the majority of energy is dissipated by plastic deformation [19,24-27].

With the exception of the notable work of Jahn et al. [4,5,17] and a few other authors $[16,28]$ there has been even less research published on the weld formation and microstructure evolution during the application of high power USW (HP-USW) systems to spot welding the thicker sheet material of interest to the automotive industry. However, it is clear that in this case extensive plastic deformation occurs within the weld zone, that is not just localised at the interface, and the process of weld formation is difficult to interpret $[5,16,17]$. In HP-USW the welding process results in the displacement of the join-line in a complex wave-like pattern $[5,16]$.

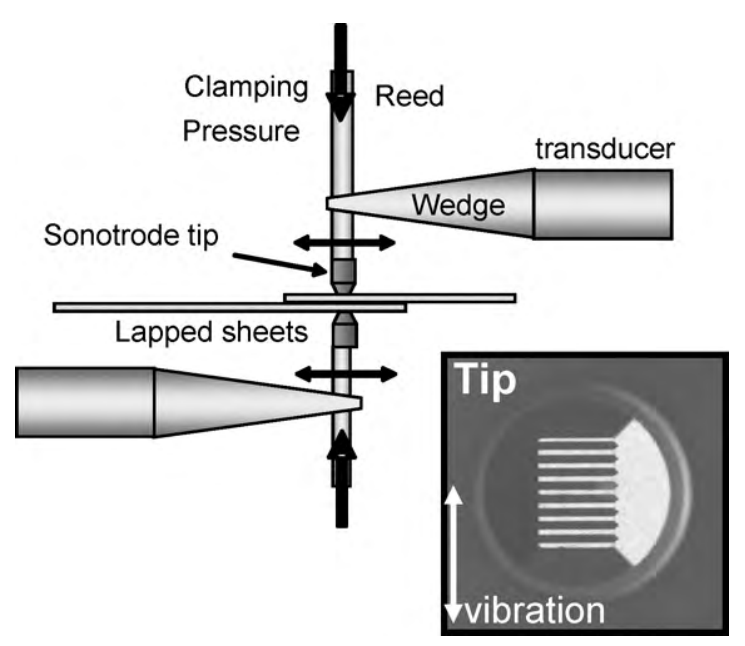

Fig. 1. Schematic diagram of the dual-reed ultrasonic welding machine, with an image of the $8 \mathrm{~mm} \times 6 \mathrm{~mm}$ sonotrode tip used as an insert.
A range of 'flow' or 'wake' features have been noted [5,16], including vortices, or swirls and spirals, as well as bifurcation of the join-line, but the origin of these effects is poorly understood. Further, the welds have been reported to contain defects including, retained oxide, porosity, and micro-cracks [5]. Heterogeneous deformation structures, commensurate with severe deformation and containing ultrafine grains and high dislocation densities, have also been observed at the weld-line [16,17], but no evidence of a heat affected zone has been reported.

The overall objective of the work, that will be discussed here, was to improve our current understanding of the mechanisms of weld formation, when HP-USW is applied to aluminium automotive sheet and the material interactions that occur in the process. To this end, we report on the results of a detailed investigation, where we have studied the material flow using dissimilar alloy combinations, combined with, X-ray tomography, and high resolution FEG-SEM and EBSD, to characterise the weld defects, stages of weld formation, and microstructure evolution, as a function of welding energy, focusing on a standard automotive material AA6111-T4 in $0.92 \mathrm{~mm}$ thick sheet.

\section{Experimental}

All the data presented is for welds produced in $0.92 \mathrm{~mm}$ thick, 6111-T4, aluminium sheet supplied by Novelis, with no cleaning or surface preparation prior to joining. The HP-USW system employed was a dual wedge-reed $2.5 \mathrm{~kW}$, Sonobond-MH2016 machine, operating at $20.5 \mathrm{kHz}$. The flat $8 \mathrm{~mm} \times 6 \mathrm{~mm}$ sonotrode tips used had serrated surfaces comprised of nine parallel ridges (or teeth) to improve gripping of the lapped sheets (see insert Fig. 1). The tips were oriented with their long dimension parallel, and the ridges perpendicular, to the vibration direction. Weld test coupons were produced using standard size $25 \mathrm{~mm} \times 100 \mathrm{~mm}$ strips, with the weld located at the centre of a $25 \mathrm{~mm}$ overlap, under a constant pressure of 31, 40 or $50 \mathrm{MPa}$ (defined as force over the whole tip area). The pressure was calibrated against a load cell. The sheets were gently clamped to avoid vibrational damping. The welding direction was perpendicular to the coupon. Different weld energies of up to $1.5 \mathrm{~kJ}$ were obtained by varying the weld time with a constant target power $(P)$ of $2.5 \mathrm{~kW}$, controlled by the USW machine. It should be noted that weld energy $(U)$ and time $(t)$ are approximately interchangeable; i.e. as $U=P \times t$. For example, $1 \mathrm{~kJ}$ at $2.5 \mathrm{~kW}$ is equivalent to $\sim 0.4 \mathrm{~s}$. In order to evaluate the mechanical strength of the joints, and establish the optimum welding conditions, tensile lap shear tests were performed on the weld coupons. Results were averaged over three tests with the peak load measured, as well as the total failure energy, from the area under the load displacement curves. Weld temperatures were measured using $0.5 \mathrm{~mm}$ diameter k-type thermocouples placed as close as possible to the sonotrode tip contact area (the position is indicated in Fig. 4) either just below the top sheet surface or imbedded, using a precision drilled hole, to contact the bottom sheet top surface (weld interface position).

X-ray tomography was used to characterise the weld quality, in terms of the interface defect areas, as a function of weld time, using a Metris HMX225 X-ray radiography set. This system had a conical X-ray beam with a maximum energy of $225 \mathrm{keV}$, and a focal spot size of $5 \mu \mathrm{m}$, giving a resolution of $\sim 6 \mu \mathrm{m}$ in aluminium. 800 radiographs were recorded on a $1024 \times 1024$ CCD. The whole weld area was scanned by cutting out the weld and fixing it to a rotating cylinder. Volume reconstruction was performed with a three-dimensional FBP (Filtered Back Projection) algorithm [29]. The welded joints were sectioned across their centre, parallel to the direction of vibration and the weld zone microstructures were characterised using a high resolution FEI Sirion FEG-SEM equipped with an HKL EBSD system. Images were obtained on unetched mechani- 
Table 2

Nominal compositions of the alloys used in this investigation.

\begin{tabular}{llllll}
\hline Alloy & $\mathrm{Mg}$ & $\mathrm{Si}$ & $\mathrm{Cu}$ & $\mathrm{Fe}$ & $\mathrm{Al}$ \\
\hline Al 6111 & 0.8 & 0.7 & 0.7 & 0.25 & $\mathrm{Bal}$. \\
Al 6082 & 0.9 & 0.8 & 0.1 & 0.25 & Bal. \\
\hline
\end{tabular}

cally polished samples, after a gentle finishing polish using colloidal silica, viewed with a Back Scattered Electron (BSE) detector, as well as after light electropolishing in 30\% nitric acid methanol solution at $-25^{\circ} \mathrm{C}(3-5 \mathrm{~s})$ using Secondary Electron (SE) imaging to better reveal specific features. EDSD orientation mapping was also carried out on weld cross-sections for the optimised welding condition, using a range of step sizes depending on the scale of the local grain structure, selected such that the step size was less than $10 \%$ of the subgrain size.

The interface migration and material flow in USW was studied by welding a similar, but lower copper level, 6082 alloy (of the same thickness) to the 6111 alloy (see Table 2 ). The 6082 aluminium alloy was selected because it has nearly the same magnesium and silicon addition levels as 6111 , but etches differentially owing to the lower copper content.

\section{Results}

\subsection{Weld optimisation}

\subsubsection{Lap shear strength}

In Fig. 2 the average lap shear strength and failure energies measured from the weld coupons are plotted against weld energy with a constant $2.5 \mathrm{~kW}$ welding power, for three different clamping pressures. Although all the results presented are for one sonotrode tip design, it is worth noting that Jahn et al. have noticed little difference in the maximum weld strength for different sonotrode knurl
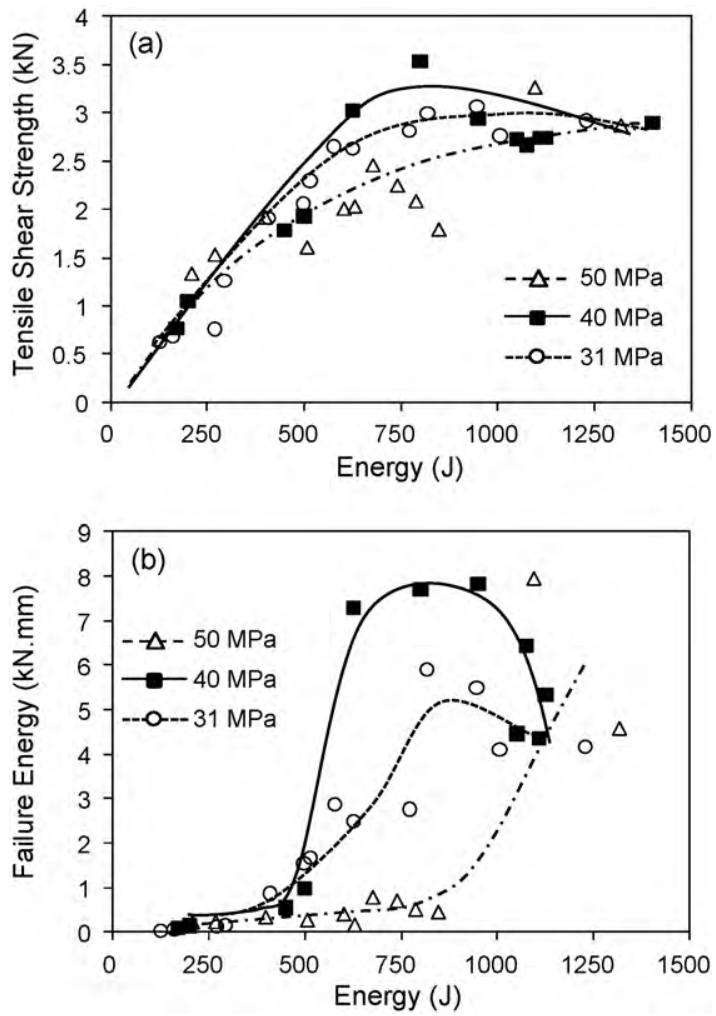

Fig. 2. The average lap shear strength (a) and failure energy, (b) plotted against weld energy, with a $2.5 \mathrm{~kW}$ welding power, for three different clamping pressures. patterns [5]. From Fig. 2a it can be seen the welds produced with the intermediate clamping pressure of $40 \mathrm{MPa}$ achieve the highest optimum strength and peak in strength at the shortest welding time of $0.3 \mathrm{~s}$, which corresponds to a welding energy of only $750 \mathrm{~J}$. For lower clamping pressures (31 $\mathrm{MPa}$ ) it takes slightly longer to reach the optimum weld strength, which is also slightly reduced, and for the highest pressure ( $50 \mathrm{MPa}$ ) weld formation was delayed and noisier results were achieved. (In general the scatter between individual measurements was in the range of $\pm 0.3 \mathrm{kN}$.) In comparison to the shear strengths, the weld failure energies exhibited more scatter (Fig. 2b) but show similar trends. The medium pressure of $40 \mathrm{MPa}$ welds again show the best performance, and the peak is less high and delayed to slightly greater weld energies with a lower clamping pressure. The failure energies also show a transition not so obvious in the shear strength data. For all the clamping pressures very low failure energies occur below a minimum threshold welding energy, which is followed by a rapid rise in failure energy with increasing welding time. With too high a pressure (50 MPa) weld formation is delayed to longer weld times and the threshold welding energy is greatly increased. Such effects are known from welding thinner materials and relate to the effect of pressure on heat generation and the sliding condition at the welding surfaces $[18,26]$. Generally, in USW heat generation increases with higher pressure because it causes a greatest resistance to sliding and more rapid microbonding, accelerating welding and energy desperation by plastic work. However, if too high a pressure is used interfacial locking can occur, whereupon the initial deformation becomes largely elastic and heat generation and bonding is inhibited [26].

The maximum strength achieved with the optimum $40 \mathrm{MPa}$ clamping pressure was $3.5 \mathrm{kN}$, which is similar to that reported for single reed welding systems operating at the same power [15] This strength level compares very favourably to the maximum reported shear strength of $\sim 3.4 \mathrm{kN}$ for the competing process of FSSW with the same alloy and sheet thickness [9,30]. Furthermore, the weld sonotrode tip area is smaller than that normally used for the FSSW tool shoulder. As the optimum weld performance was achieved with a clamping pressure of $40 \mathrm{MPa}$, all of the analysis performed below will be for samples produced using this applied pressure.

\subsubsection{Failure behaviour}

Examples of the fracture surfaces of typical lap shear test coupon's are shown in Fig. 3, for welds produced with an applied pressure of $40 \mathrm{MPa}$, where it can clearly be seen that there is a change in failure mode from interface debonding, or cleavage, at the weld-line for low energies (Fig. 3a-c) to nugget pullout for the optimum (Fig. 3d) and higher energies. This transition coincides with the threshold welding energy at which the weld failure energy begins to rapidly rise (Fig. 2b) and is associated with a dramatic increase in failure energy that results from the plastic deformation required to tear out the weld nugget, as opposed to that involved in interface cleavage, or peeling.

In the initial stage of bonding at low welding energies (150 J in Fig. 3a) small bright spots, resulting from ruptured microwelds, can be seen to have formed concentrated near the edge of the sonotrode tip footprint. The ruptured microwelds are shown at a higher magnification in Fig. 3a and are elongated in the direction of weld vibration, as well as being aligned parallel to the rolling marks. As the weld time increases, the area covered by microbonds expands (Fig. 3b) and their density rises. Eventually bonding occurs over the majority of the sonotrode tip foot print (Fig. 3c), where upon the net bonded area becomes so large that it is no longer possible to separate the sheets and weld pullout takes place (Fig. 3d). 

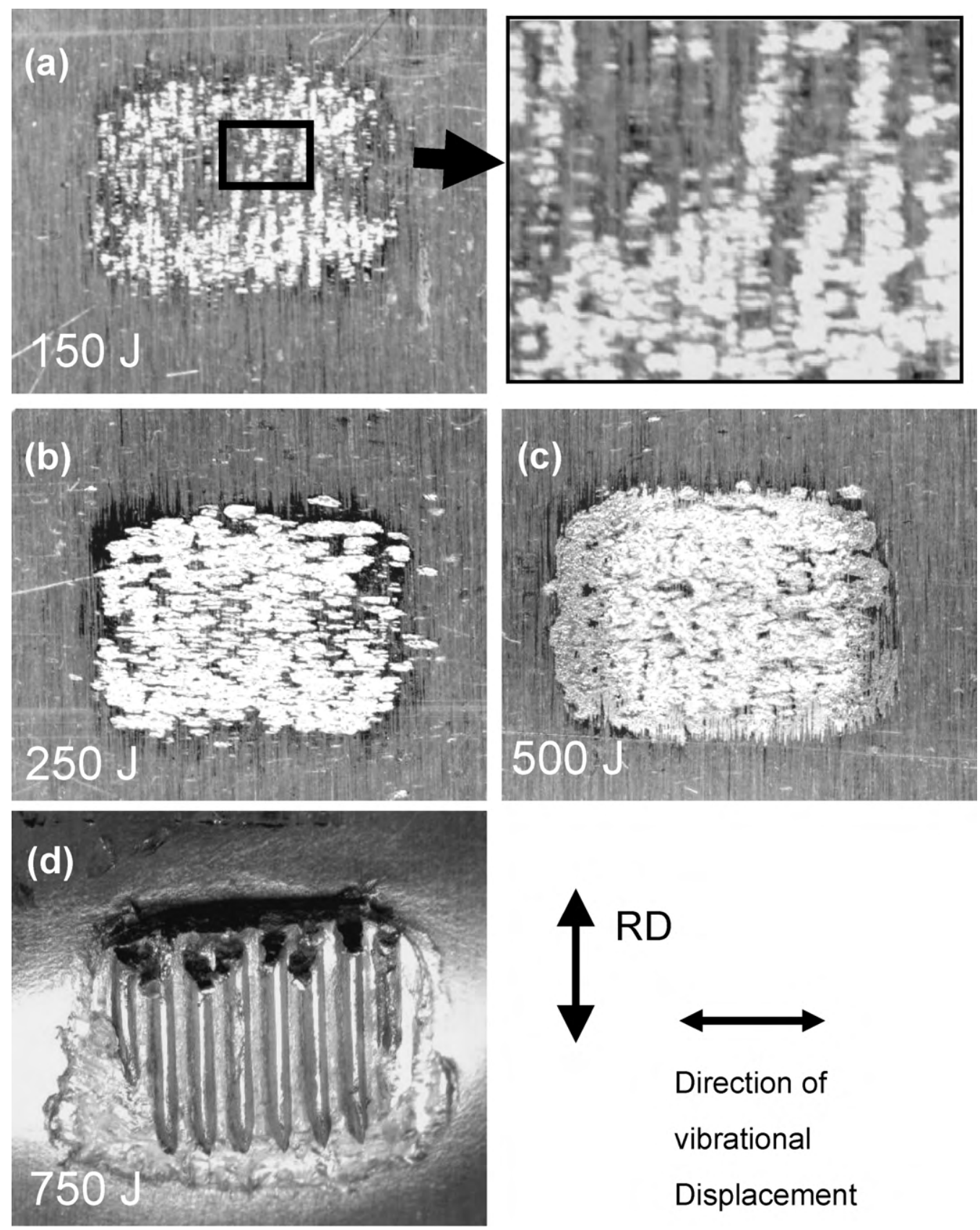

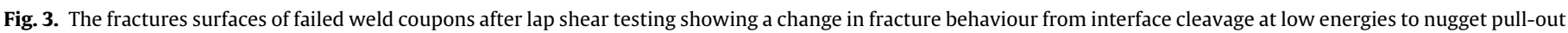
at higher weld energies: (a) $150 \mathrm{~J}$, (b) $250 \mathrm{~J}$, (c) $500 \mathrm{~J}$ and (d) $750 \mathrm{~J}$, with ruptured mirobonds shown enlarged in (a).

\subsection{Thermal measurements}

Because of the small size of the welds, and rapid weld time, there is limited published data on thermal measurements in USW [21]. Results from measurements of the USW thermal weld cycle, using thermocouples placed as close as possible $(\sim 0.2 \mathrm{~mm})$ to the edge of the sonotrode tip at the top sheet surface and weld-line, are depicted in Fig. 4, for the welds produced with the optimum $40 \mathrm{MPa}$ pressure. In this position at the weld centreline the maximum temperatures recorded by the thermocouples rose from only $74^{\circ} \mathrm{C}$, for $180 \mathrm{~J}$, to $277^{\circ} \mathrm{C}$, with the optimum weld energy of $710 \mathrm{~J}$, and to $391{ }^{\circ} \mathrm{C}$, at the maximum weld energy of $1000 \mathrm{~J}$. At the sheet surface the temperatures were $20-50{ }^{\circ} \mathrm{C}$ lower. In the low power range the results are consistent with other data on thinner materials (e.g. [21]) and model predictions [19,27]. The measurements confirm that the thermal cycle in USW is very short, even relative to FSSW, with the material also experiencing lower peak temperatures [9]. The curves show that the temperature rises extremely quickly, reaching a maximum in a time equivalent to the duration over which power is applied (e.g. $0.34 \mathrm{~s}$ for a $700 \mathrm{~J}$ weld). The heating rates are thus very rapid, being of the order of $800 \mathrm{k} \mathrm{s}^{-1}$. The cooling rates are also high, owing to the low heat input and high conductivity of aluminium sheet, with the temperature falling to below $100^{\circ} \mathrm{C}$ in under $3 \mathrm{~s}$ and down to $50^{\circ} \mathrm{C}$ in only $14 \mathrm{~s}$ even for the highest energy weld. It has not yet been possible to measure the weld temperatures at the centre of the weld between the sonotrode tips. Modelling by Elangovan et al. [19] predicts that the peak temperature will be higher at the contact surface of the sonotrode tips, but will be hottest at the weld join-line where it might be expected to be at least $100^{\circ} \mathrm{C}$ greater than where the thermocouples were 


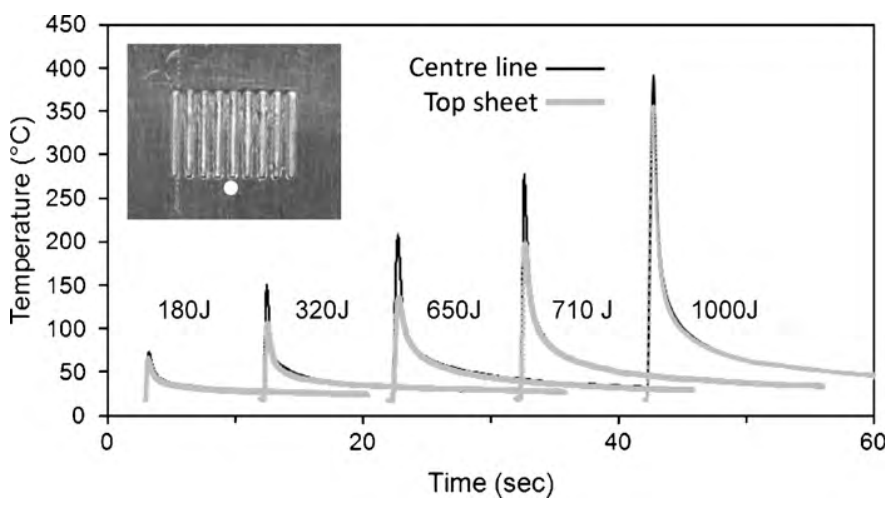

Fig. 4. Thermal measurements obtained as close as possible $(\sim 0.2 \mathrm{~mm})$ to the edge of the sonotrode tip, at the top sheet surface and weld centre line, with a clamping pressure of $40 \mathrm{MPa}$, for increasing welding energies. Note: the curves are displaced for clarity. The measurement position is indicated by the white circle in the insert. placed. For the optimum welding energy this would therefore be around $380^{\circ} \mathrm{C}$. Such temperatures are sufficient to result in a dramatic loss of strength in alloys like 6111. For example the yield stress of 6063 falls to $\sim 14 \mathrm{MPa}$ at around $370^{\circ} \mathrm{C}$ [31].

\subsection{Weld cross-sections}

Carefully etched optical images are shown of whole weld crosssections in Fig. 5 with increasing welding energies (or weld time). For short weld times the weld foot print is not clearly visible, because the temperature has not yet risen sufficiently for the material to soften enough to significantly plastically deform under the ridges of the sonotrode tip. The width of the sonotrode tip has, therefore, been marked with a white line. As the welding energy and temperature rises, the teeth start to penetrate into the sheet surface reaching their full depth at around $700 \mathrm{~J}$. With longer weld times, and increasing energy, the full sonotrode tips penetrate into the lapped sheets from either side of the weld (Fig. 5e). This leads to thinning of the sheets in the weld area, as well as the expulsion
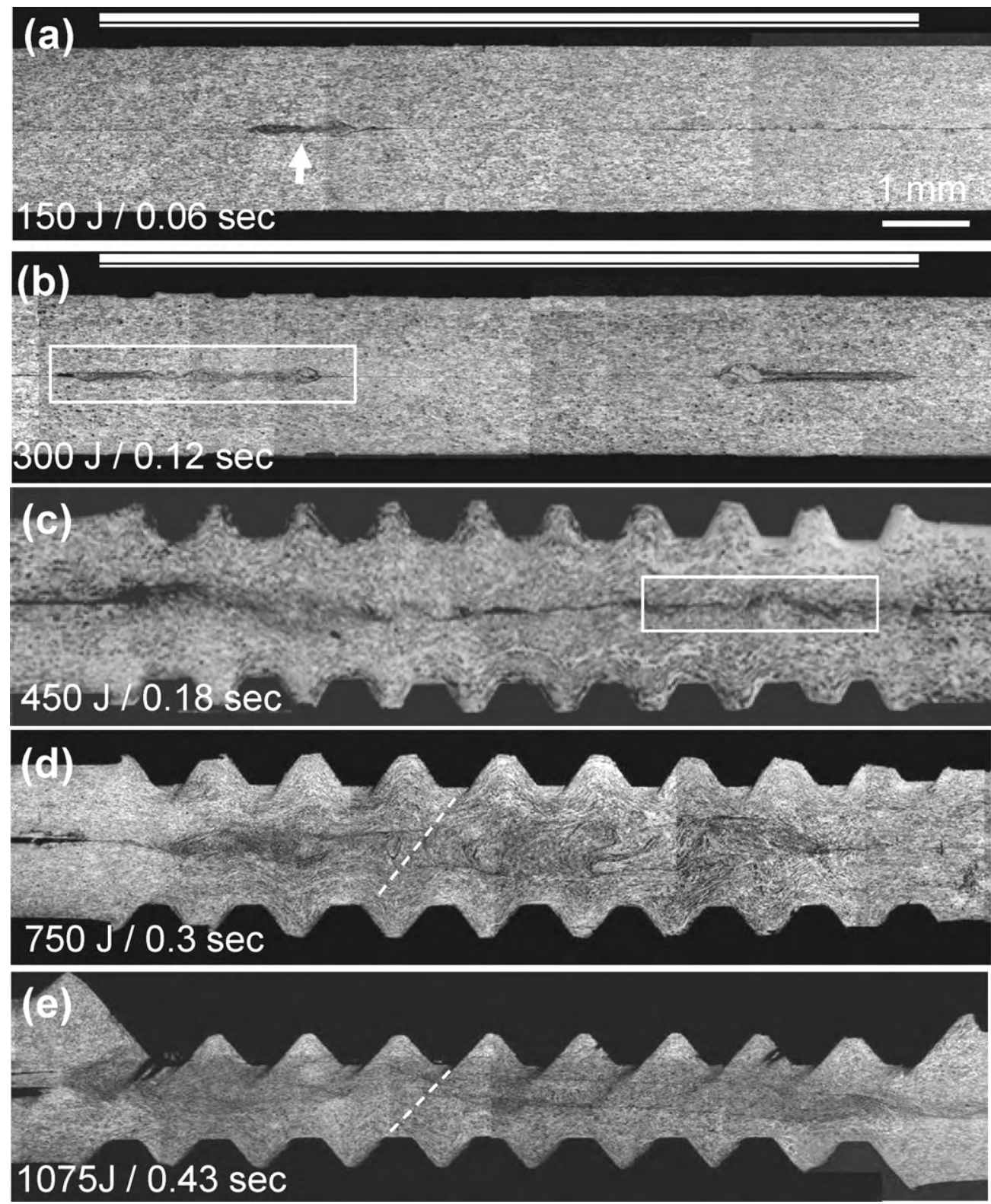

Fig. 5. Etched optical images of 6111 weld cross-sections produced with a pressure of $40 \mathrm{MPa}$, with increasing weld energies (or weld time): (a) $150 \mathrm{~J} / 0.06 \mathrm{~s}$, (b) $300 \mathrm{~J} / 0.12 \mathrm{~s}$, (c) $450 \mathrm{~J} / 0.1 \mathrm{~s}$, (d) $750 \mathrm{~J} / 0.3 \mathrm{~s}$, and (e) $1075 \mathrm{~J} / 0.43 \mathrm{~s}$. The highlighted areas are enlarged in Fig. 7. 

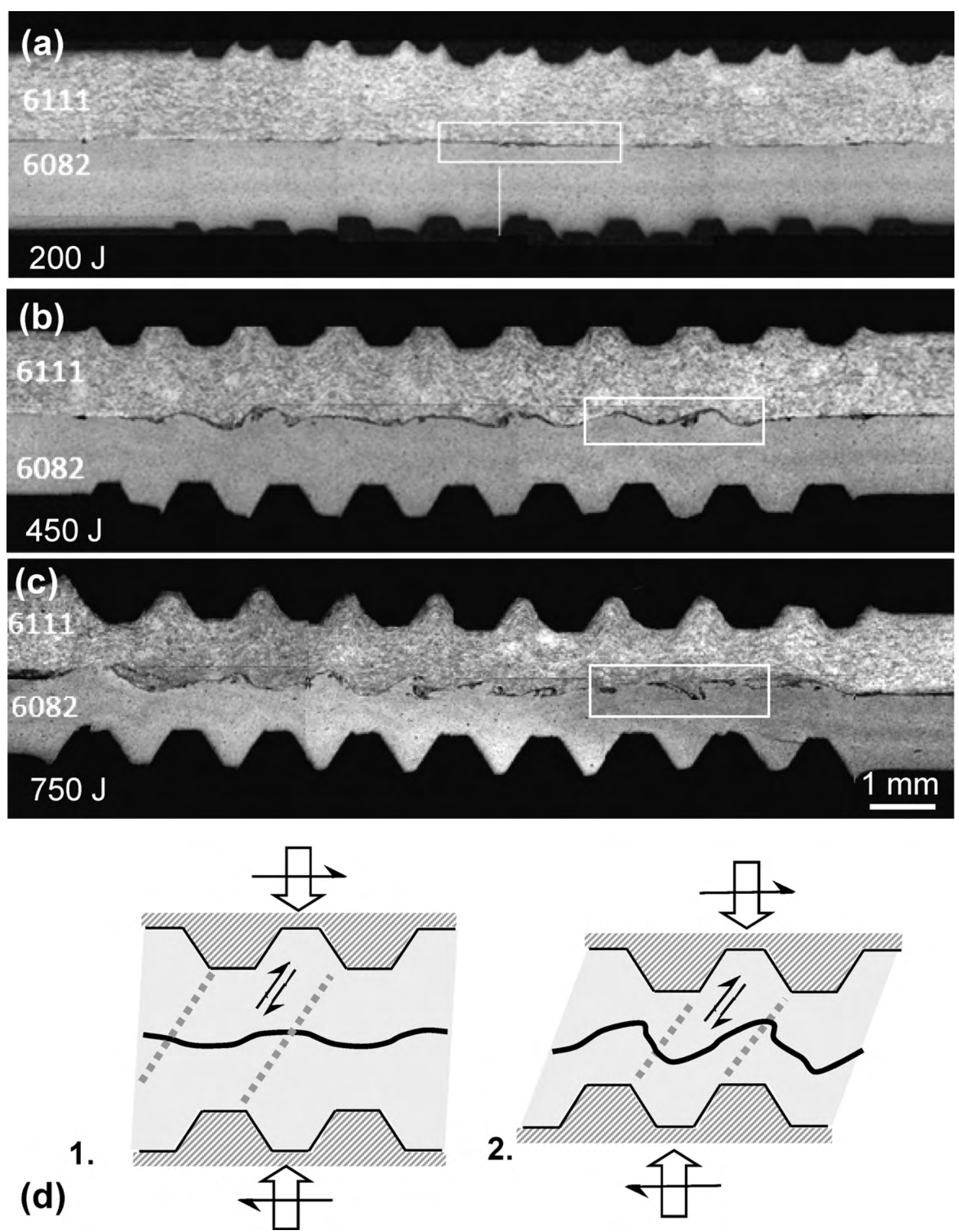

Fig. 6. Cross-sections of ultrasonic welds produced between dissimilar alloys (6111 and 6082) with similar mechanical properties, but different copper contents, to allow the weld interface to be revealed by differential etching: for (a) low (200 J), (b) medium (450 J) and (c) an optimum weld energy (750 J), all with a $40 \mathrm{MPa}$ applied pressure. The highlighted areas are enlarged in Fig. 7. In (e) a schematic diagram depicts the development of the macroscopic interface displacement wave.

of some flash, and is the principle reason for the joint performance decreasing past the optimum weld time (Fig. 2) when failure occurs by nugget pullout.

It can further be seen in Fig. 5 that weld formation initially develops heterogeneously at specific regions under the tool, with plastic deformation highly localised to the interface between the two sheets (dark areas in Fig. 5a and b). In Fig. 5a the first area to bond (arrow) is under the second- tooth in from the tool edge. The bonding then expands outwards to the tool edge, as well as inwards, until it spreads across the whole interface (in agreement with the fracture surfaces shown in Fig. 3). With increasing energy there is a dramatic change in behaviour above around $500 \mathrm{~J}$ when plastic deformation becomes more extensive and expands throughout the weld region (Fig. 5d). This occurs as a result of bonding spreading fully across the join-line and the rapid softening of the material as the temperature rises. At low energies when plastic deformation is localised to the interface, and microbonding predominantly occurs, the weld join-line remains macroscopically flat 

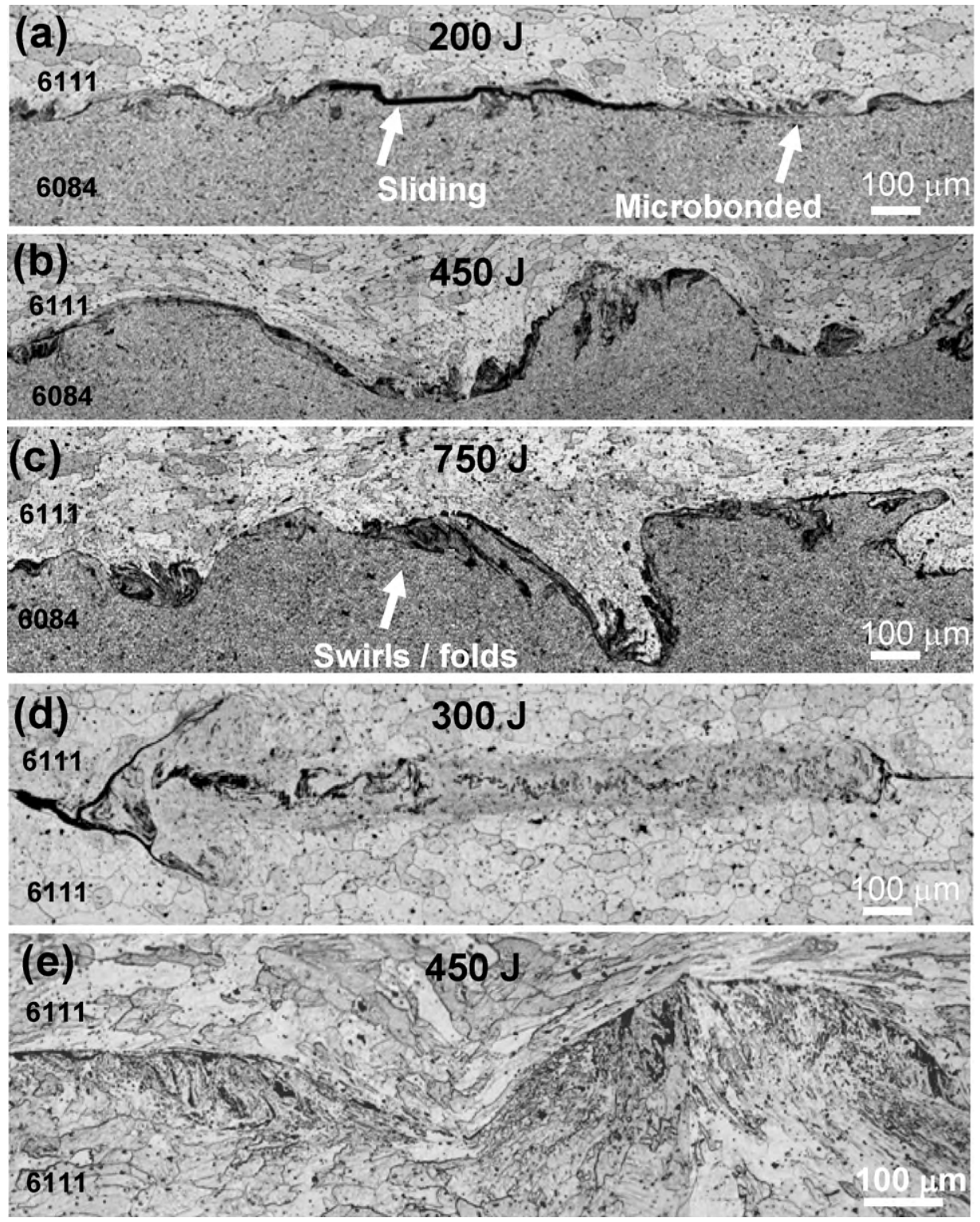

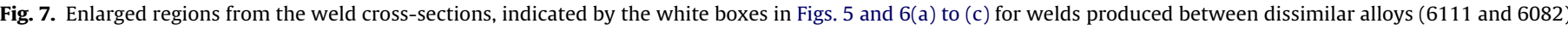

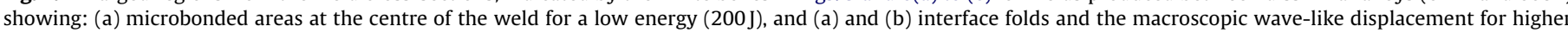

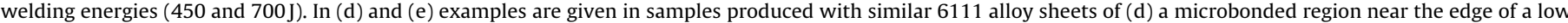
energy weld $(300 \mathrm{~J})$ and (e) interface folds in a $450 \mathrm{~J}$ weld.

and its appearance is typical of that seen in conventional ultrasonic welding at low powers [26]. However, as the weld energy increases above $\sim 500 \mathrm{~J}$, and the plastically deforming region expands, the weld-line becomes macroscopically displaced developing a convoluted wave-like appearance. This behaviour, previously discussed by Jahn et al. [5], is characteristic of high power USW and will be explored further below using dissimilar alloy sheets, which allow the interface position to be visualised more clearly (Fig. 6).

At high energies (Fig. 5d and e) coupling of the teeth with the surface can be seen to induce macroscopic shear bands at around $45^{\circ}$, which try to develop between opposing teeth tips, where the path of material resistance is least, due to the local reduction in thickness and the concentration of stress. At an energy of 700 J, (Fig. 5d) shear bands can be seen between teeth offset by one pitch, but as the sheet thins with higher welding energy the pattern changes to shearing between teeth that were originally directly above each other, but that have become displaced so that they are now exactly out of phase and are aligned in male-female registry (Fig. 5e). There is thus a progressive relative displacement of the sonotrode tips out of alignment as the welding time increases.

\subsection{Material flow behaviour}

The material flow in high power USW spot welding results in a wave-like displacement of the interface accompanied by complex deformation that has been described globally as forming "wake features" near the join-line [5]. These structures have been reported to involve vortices, ripples, and spiral like patterns $[5,16]$. Here, we have tried to clarify some of these observations by welding 6111 to a dissimilar alloy, 6082, with similar mechanical properties, but a lower copper content, to allow the position of the weld interface to be more rigorously identified by differential etching. From the macro-views of the weld cross-sections in Fig. 6 it can be clearly seen that a coarse scale wave-like displacement of the join-line develops at high weld energies, the wavelength of which coincides 

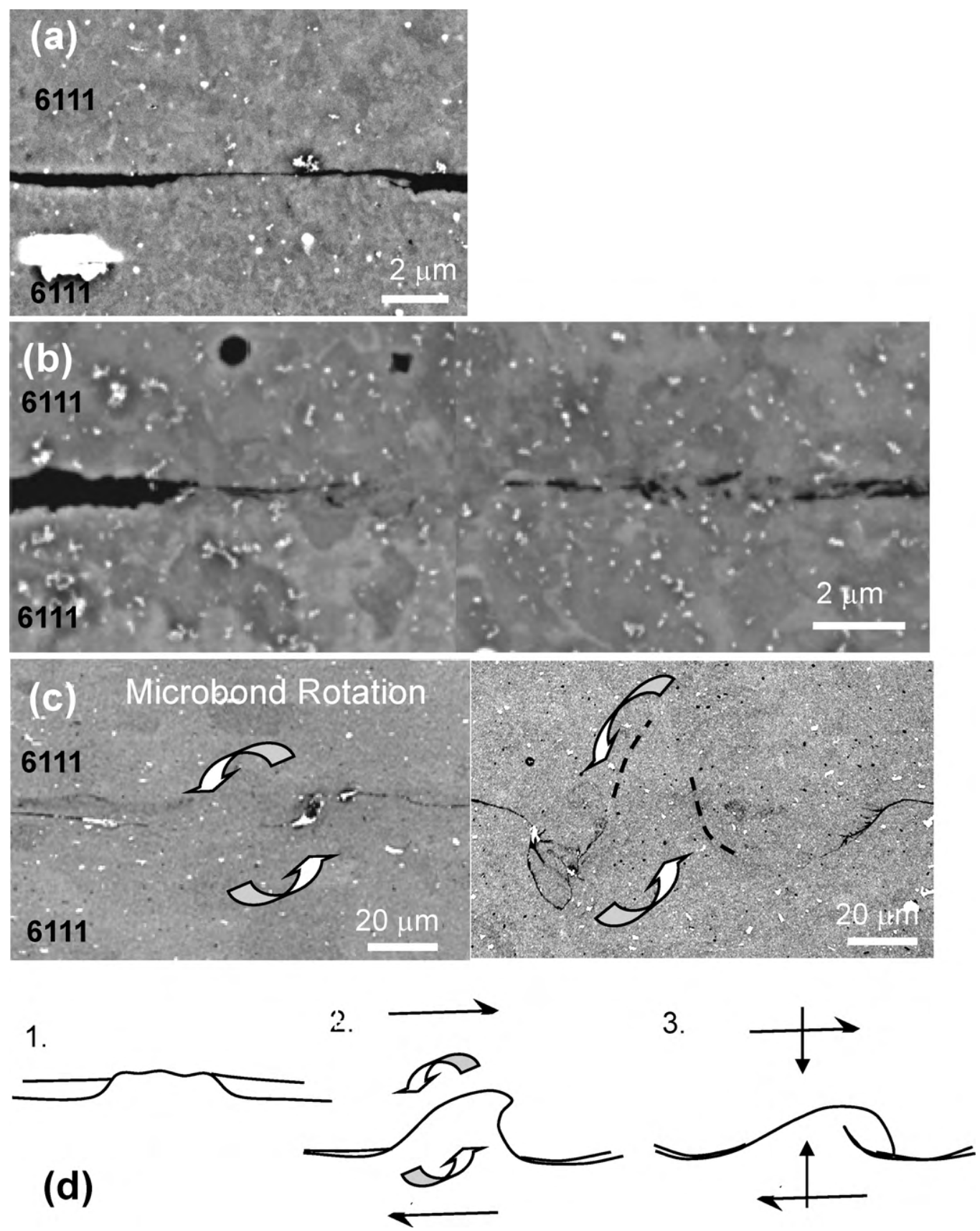

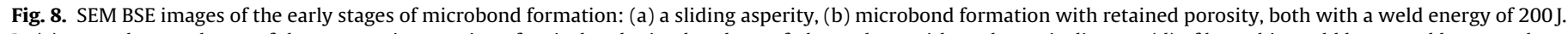

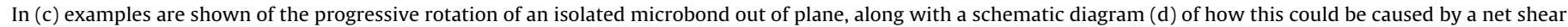
displacement at the weld interface.

with the spacing of the teeth on the sonotrode tips. Highlighted regions in Fig. 6 are depicted at higher magnification in Fig. 7, and examples of specific phenomena are illustrated in Figs. 8 and 9, which will be returned to in the discussion. In Fig. 7a it can be observed that for low weld energies, when plastic deformation is localised to the weld-line, the bond line develops roughness on a length scale which is much finer than the spacing of the teeth (see also Fig. 7d). At this stage large areas of the interface have not yet bonded, (e.g. Figs. 7a and 8a) and are in a sliding condition, while other areas have formed microbonds (Figs. 7d and 8b). In the microbonded regions the interface rapidly becomes convoluted and locally displaced, by rotation of the bonded segments (Figs. 7d, 8c and d).
With higher energies, as the sonotrode tips sink further into the sheets, the coarse scale wave-like displacement becomes more extreme (Fig. 6c), and the wave peaks develop crests, or folds, in some regions. At high weld energies the differentially etched images in Fig. $7 \mathrm{~b}$ and $\mathrm{c}$ also give evidence of finer scale interface folds, or swirls, superimposed on the coarse wave-like displacement, where the two materials have become intercalated. These features are identical in the conventional similar 6111 alloy weld (Fig. 7e) and when magnified in Fig. 9a they appear to develop from the first microbonds seen at lower energies (Figs. 7a and $8 b-d$ ). In the electro polished SEM-SE images in Fig. 9b they can be seen to be close in appearance to the vortices reported by Jahn et al. [5] and contain a high 

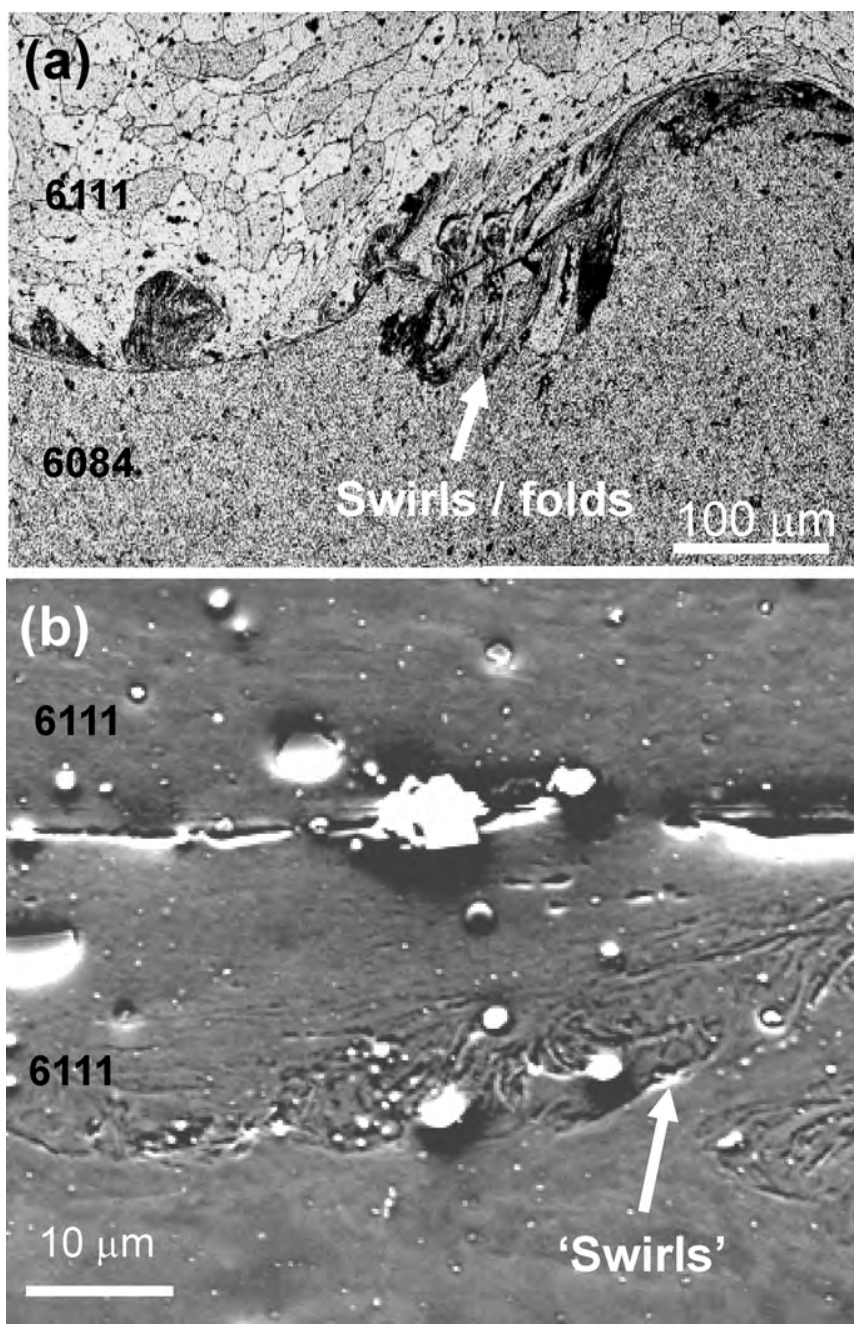

Fig. 9. (a) A higher magnification view of an etched optical image of a dissimilar alloy weld showing interface folds/swirls compared to (b) an SEM-SE image from an electropolished conventional 6111 weld depicting similar features.

local density of oxide and intermetallic particles delineating flow lines.

\subsection{Weld defects}

Because interpreting defects in welds from single 2D sections can be misleading, 3D X-ray tomography was used to reconstruct the entire weld volume for joints produced with a medium energy $(350 \mathrm{~J})$ and the optimum energy weld $(750 \mathrm{~J})$. It should be noted that the tomography system used was limited to a resolution of $\sim 6 \mu \mathrm{m}$ and could, therefore, only reveal interfacial voids, or unbonded areas, where the sheet surfaces were not in intimate contact. Nevertheless, when supported by higher resolution SEM analysis this technique revealed important information on the process of weld formation. For the lower energy weld a substantial density of defects, or unbonded areas, were observed (Fig. 10a). These defects appeared to be dispersed randomly over the weld area, which is presumably because at this stage join-line is not really influenced by the locally higher pressure under the sonotrode tip teeth. Further, because of the resolution limit of the instrument when the temperature is too low for gross plastic flow the interface is macroscopically flat and the unbonded areas maybe too thin to be fully characterised. For example, the more bonded areas near the edge of the tool were not clearly identified. With a medium weld energy (Fig. 10b), although some unwelded areas are still clearly missed,
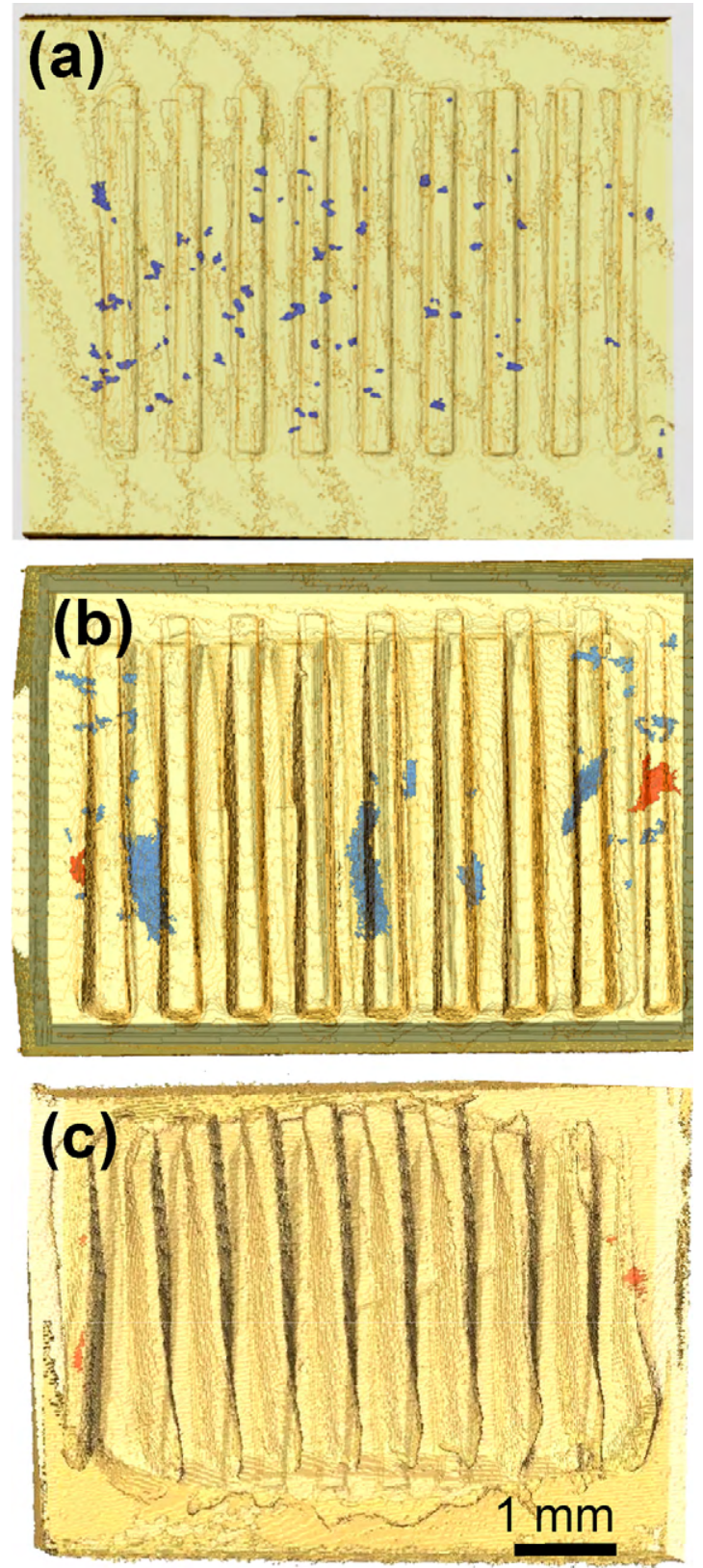

Fig. 10. 3D X-ray tomographic reconstructions depicting the entire weld area in plan view: in (a) from a low $200 \mathrm{~J}$, (b) a medium $350 \mathrm{~J}$, and (c) $750 \mathrm{~J}$ optimum energy weld.

two types of larger flaw could be resolved; approximately planar wavy defects, and more elliptical folds. The latter flaw was seen at the edge of the weld region and matched the large defects at this position found in the optical sections (e.g. Fig. 7d). The more planar defects were often inclined at an angle, due to the macroscopic wave-like displacement of the weld-line, and can be seen to be in areas of lower pressure being concentrated between the teeth imprints on the flanks of the interface waves. By the time the optimum weld energy had been reached, no large planar defects could be resolved in the centre of the weld by tomography and only the remnants of the large flaws found at the edge of the weld area remained (Fig. 10c).

When viewed at a higher resolution in cross-sections by SEM, as well as the large unbonded areas present in the lower energy welds, localised unbonded regions were also found between microwelds in regions where bonding had initiated at low weld energies (e.g. Fig. 8b). For medium energies substantial unwelded areas could still 

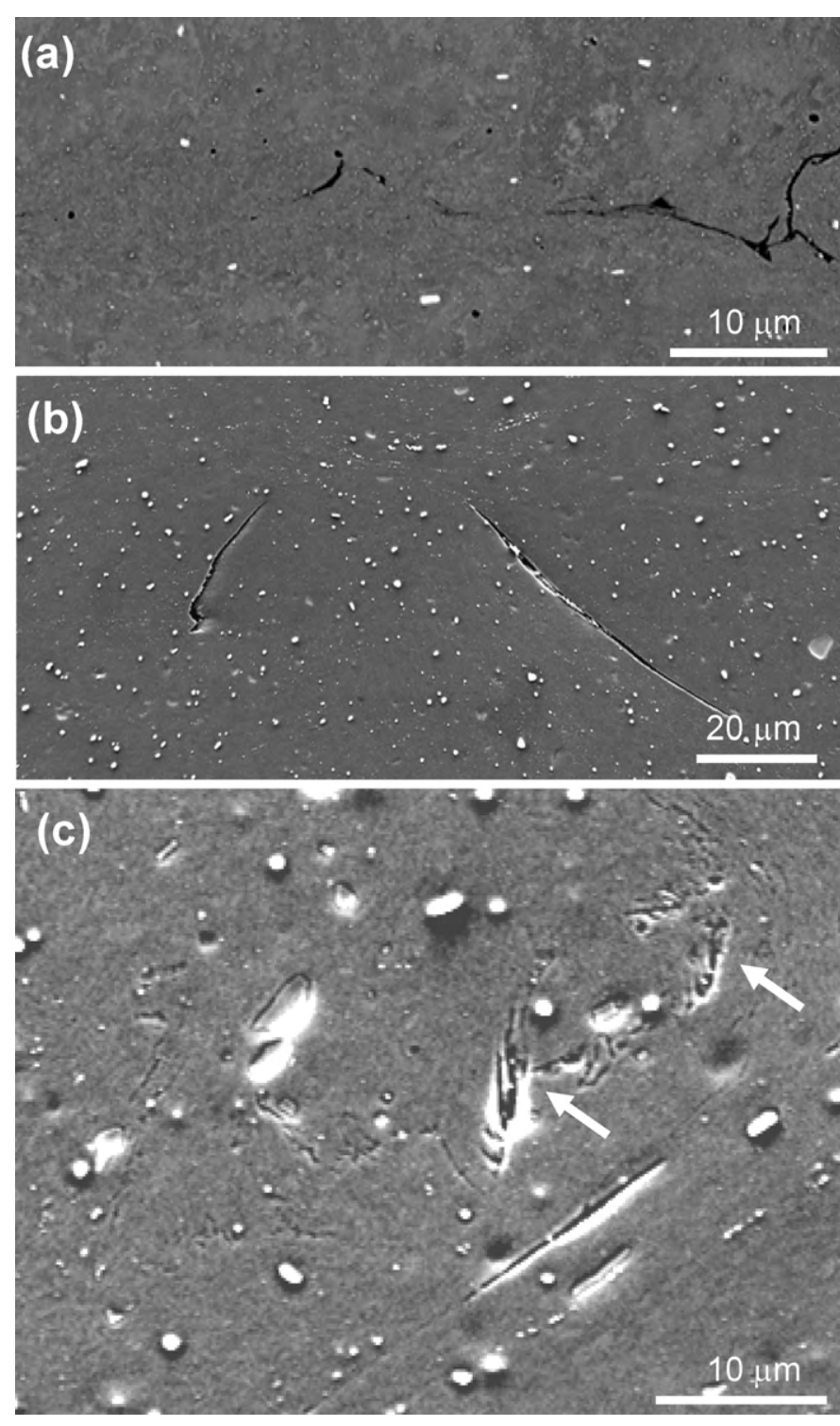

Fig. 11. Fine cracks, or unbonded areas, seen at the weld-line by SEM imaging for: (a) a $450 \mathrm{~J}$ weld (BSE image) and (b) the $750 \mathrm{~J}$ optimum condition (SE image), where the unbonded cracks are clearly associated with the sides of waves generated from the macroscopic displacement of the weld interface. In (c) possible porosity associated with an interface 'swirl is indicated in a lightly electropolished sample (SE image).

be found in metallographic sections (Fig. 11a) but at the optimum weld energy (750 J) few unbonded areas remained. Only the occasional localised defect could still be seen at the weld-line (Fig. 11b). These defects again tended to be associated with the flanks of the waves generated from the displaced interface, which are in areas of lower pressure, being located in between the sonotrode teeth. However, they were relatively rare and, within a given section, the average total unbonded crack length was less than $5 \%$ of the interface line length.

As well as the presence of cracks, or unwelded areas, Jahn et al. [5] have demonstrated the occurrence of 'foam like' porosity in vortices within the interface region of USW welds, produced under similar conditions and in the same material investigated. In the welds produced here, under optimum conditions, less evidence was found of porosity, in unetched or lightly electropolished SEM samples, which suggests that these defects may be exaggerated by sample preparation. Light electropolishing of areas closer to the interface revealed similar 'swirl' features to those reported by Jahn et al. where extensive deformation had occurred and pitting was evident associated with second phase particles, but little porosity (Fig. 9c). In specific areas, regions were found which exhibited interconnected pores (arrow in Fig. 11c). This porosity appeared to be associated with the interface folds and possibly also the trapping of debris at the bond lined (see below).

\subsection{Oxide dispersal and interfacial debris}

High resolution FEG-SEM has been used to identify the behaviour of the oxide at the interface (Fig. 12). It should be noted that SE imaging after electropolishing tends to exaggerate the appearance of the interfacial oxide (e.g. Fig. 12b) whereas BSE imaging without etching gives a more realistic assessment of the actual volume fraction and size of the oxide particles (black dots in Fig. 12c and d). In Fig. 12b the etch pits give an indication of the fine scale convoluted weld interface or complex oxide dispersal that occurs at the weld-line at low weld energies $(300 \mathrm{~J})$, while in comparison the oxide is identified unambiguously in unetched samples by SEM-BSE, in Fig. 12c and d. In Fig. 12c, showing a microbonded area for a low weld energy ( $\sim 200 \mathrm{~J}$ ), a fine scale irregular wave-like dispersion of oxide particles can be seen, which has an amplitude of around $5 \mu \mathrm{m}$. This implies that when microbonding first occurs there is an extremely fine scale dispersion of the oxide at weld interface. The oxide distribution is shown within a typical interface 'swirl' at the higher optimum weld energy (750 J) in Fig. 12d, where the oxide particles are far more dispersed and difficult to relate to the interface position.

Some evidence of interface debris was also occasionally identified within welds at intermediate weld energies. In Fig. 12a, within an unbonded crack similar to in Fig. 11a, trapped metal/oxide flakes can be seen, which are shown at a higher magnification along with an EDX oxygen distribution map from the same area.

\subsection{Grain structure}

EBSD orientation mapping has been used to analyse the grain structure generated within the weld zones in the USWs - to help better understand the deformation that occurs during the bonding process. In Fig. 13 a representative slice is shown across the centre of a weld produced under the optimum conditions and areas of interest are highlighted at higher magnifications, using progressively finer step sizes, with good indexing (>80\%). The EBSD data reveals that there are three zones apparent in the weld: (i) close to the interface where there is irregular flow and a high level of deformation occurs, either in a thin band either side of the weld-line, or within swirl-like features (Fig. 13b); (ii) a shear zone, associated with the coarse interface displacement wave, with shear bands at $\sim 45^{\circ}$ (Fig. 13c); and (iii) a forged zone, where the surfaces of the sheet have been largely deformed in compression, and the serrated sonotrode tip's have sunk into the material when it softens as the temperature rises. In zone (i) within the 'swirls' and interface region a fine structure can be seen consisting of a mixture of small $(\sim 2 \mu)$ grains and subgrains. There are also ultrafine grains within some of the shear bands in zone (ii), but in a lower density and this region has clearly undergone less deformation than at the immediate weld-line. Subgrains were also apparent throughout the zone between the sonotrode tips, which confirms that some plastic deformation had occurred throughout the entire weld region. Overall the weld zone is thus indicative of a recovered deformation structure, with local regions near the join-line showing evidence of severe deformation leading to the formation of fine grains of a similar size to the subgrains $[32,33]$. Towards the sheet surfaces, the distorted parent grain structure can be seen and the flow pattern is consistent with deformation induced by the impression of the teeth. In Fig. 13b there is also an indication of the macroscopic shear banding noted in Fig. 5, extending up to the tool surface and 

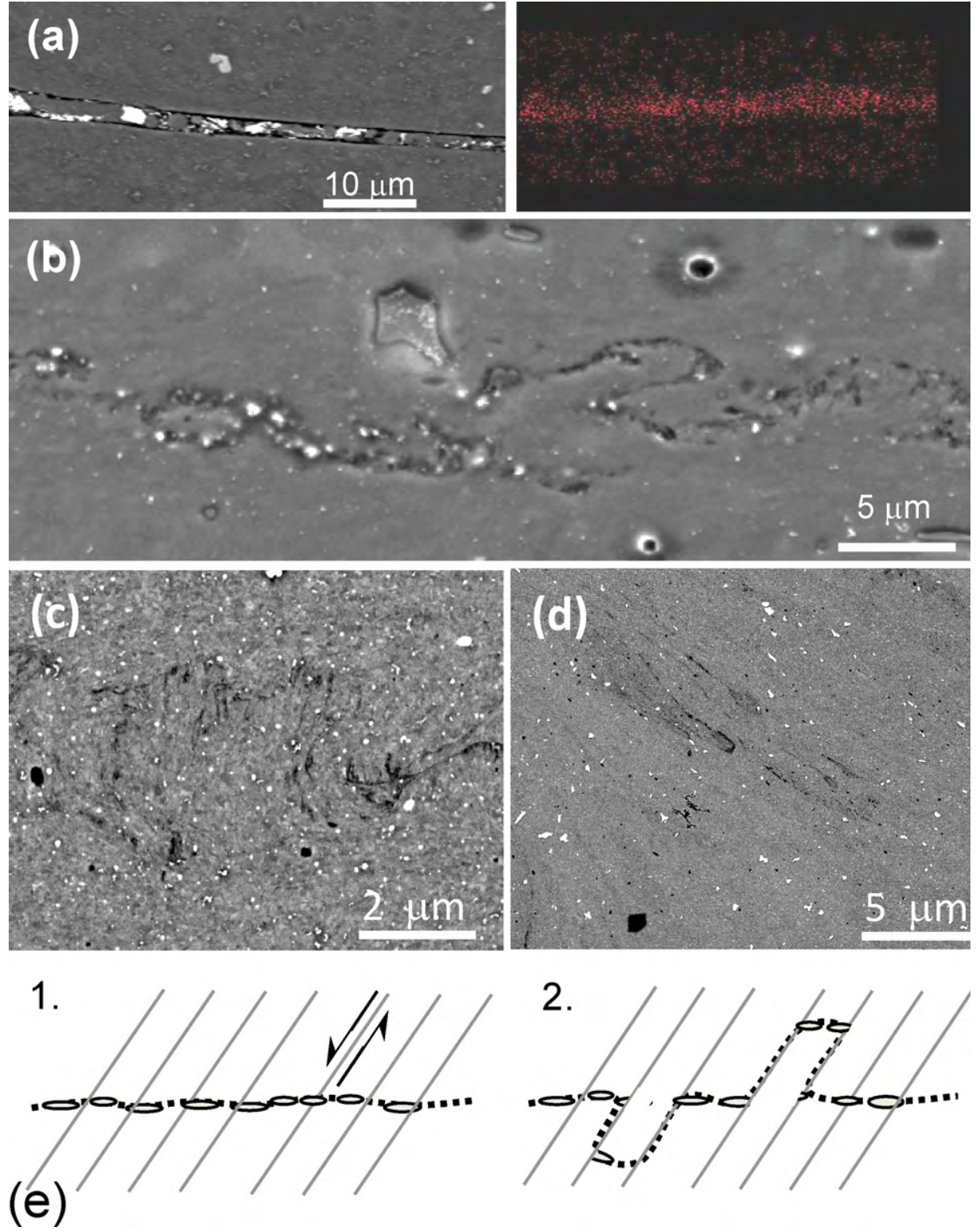

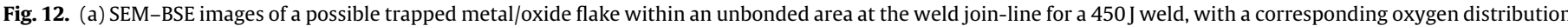

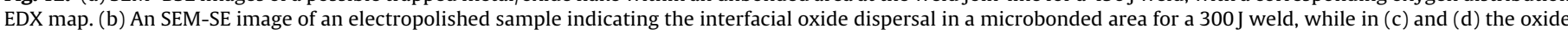

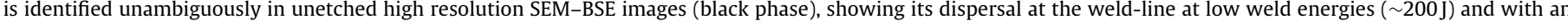
optimum weld energy (750 J), respectively.

connecting with the troughs caused by the ridges on the sonotrode tips (dashed line).

\section{Discussion}

The joint formation in ultrasonic welding of metals is a complex process which occurs very rapidly under conditions of high pressure and high frequency, low amplitude, cyclic deformation, caused by ultrasonic vibration. In conventional USW it is generally found that the deformation is restricted to the immediate weld-line $[18,26]$ and bonding is dominated by the contact mechanics at the interface and arises due to break-up of the interfacial oxide $[25,26]$. With the use of high power systems it is apparent that the material heats up to such a degree $\left(>380^{\circ} \mathrm{C}\right)$ that it becomes sufficiently soft for the weld zone to undergo plastic deformation across the entire region between the two sonotrode tips, although this is still concentrated at the weld-line. The additional compressive deformation caused by the tips clearly plays a significant role. Indeed, the devel- opment of high weld strengths and failure energies is associated with a transition from weld-line cleavage failure to weld nugget pullout. This only occurs at high weld energies when plastic deformation spreads to the whole weld zone, rather than just at the join-line, resulting in a macroscopic wave-like displacement of the interface.

EBSD analysis of the weld zone (Fig. 13) confirms that plastic deformation occurs throughout the entire zone between the anvil teeth at high welding energies. In certain regions close to the interface the deformation structure is consistent with very high plastic strains being reached, and there is also evidence of shear bands within the welds. While published work on identical materials, with similar welding parameters, suggests that recrystallisation occurs in HP ultrasonic welds [17], the majority of the microstructure observed here appeared to predominantly contain subgrains and would thus be better described as a recovered deformation structure. Regions were, however, seen where ultrafine grains had developed within areas of high local strain; for example, within 

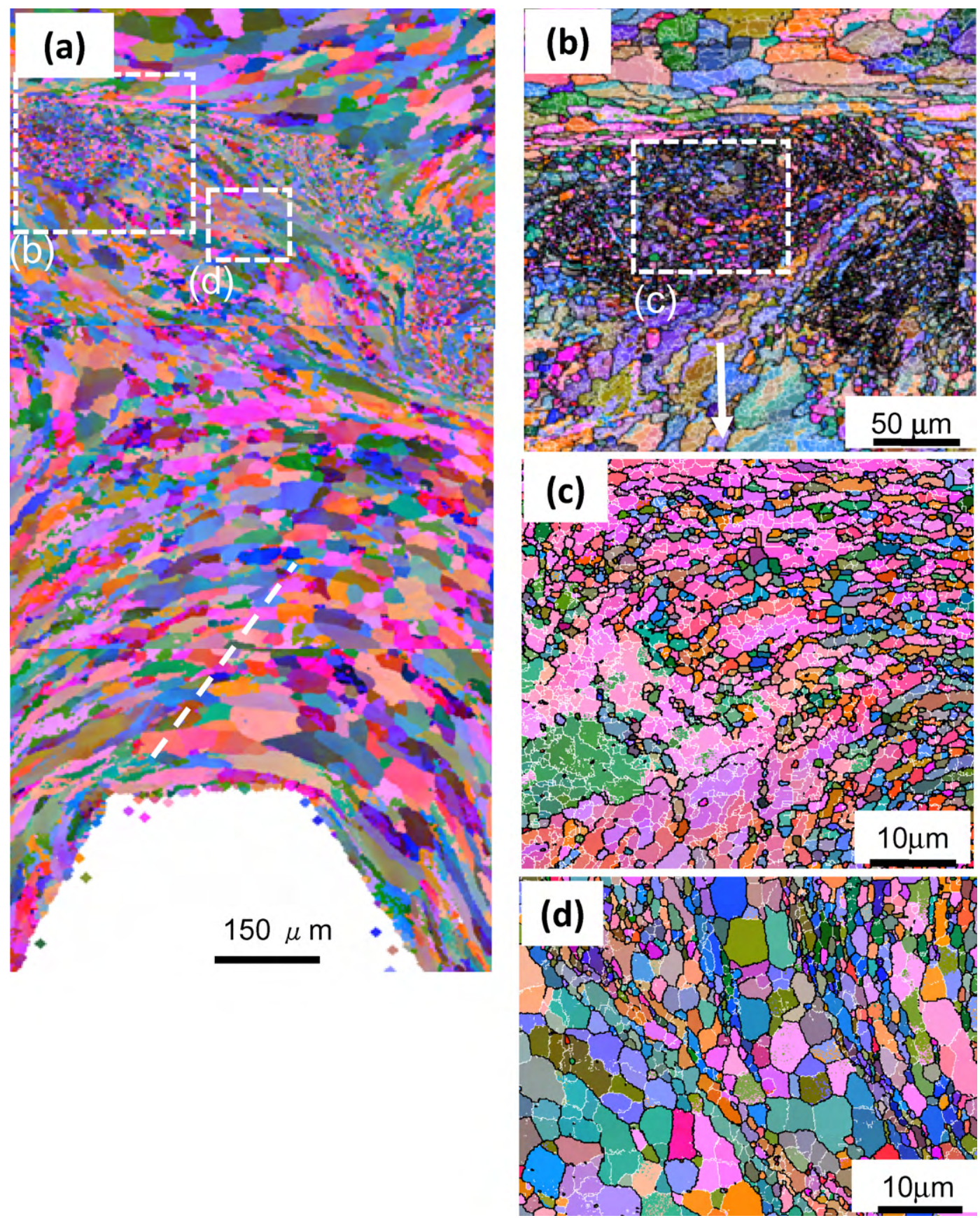

Fig. 13. EBSD orientation maps (Euler contrast) from a weld produced under optimum conditions ( $750 \mathrm{~J}, 40 \mathrm{MPa}$ ) showing: (a) a typical slice through the weld centre, (b) an interface 'swirl' and the grain structure it contains at a higher magnification, (c) and (d) shear bands close to the weld-line. Where depicted, high angle boundaries $\left(>15^{\circ}\right)$ are shown by dark lines and subgrain boundaries by light grey lines.

shear bands or close to the weld interface. The mechanisms by which such fine grains form have been previously discussed in terms of FSW and probably involves a dynamic recrystallisation process [32].

In high power USW the power $(2.5 \mathrm{~kW})$ is applied aggressively in a short space of time $(<0.5 \mathrm{~s})$ over a small tip area with a power density of $\sim 5 \times 10^{7} \mathrm{~W} / \mathrm{m}^{2}$, to a system where there is unlikely to be perfect alignment and completely uniform pressure under the sonotrode tips. In a typical $700 \mathrm{~J}, 0.3 \mathrm{~s}$, optimised weld, the weld zone undergoes $\sim 6000$ deformation cycles, with an amplitude of $\sim 20-40 \mu \mathrm{m}$ [21]. If the vibration is in the plane of the interface, and confined to a thin $50-100 \mu \mathrm{m}$ layer, this would result in significant shear strain amplitude of the order of $0.2-1$ in the microbonded interface zone. However, it is not clear to what extent dynamic coupling of the ultrasonic vibration with the lapped sheets results in out of plane vibrational forces.

In comparison, compression between opposing teeth from the sonotrode tips would result in a net average compressive strain through the sheet thickness in the range of $0.2-0.4$, for weld energies of 700-1000 J. There is thus a significant forging effect in weld formation. As the temperature will not be uniformly distributed, being higher at the faying surfaces, at least in the early stages of welding, and the sonotrode tips are serrated, this will of coarse be heterogeneously distributed and higher near the weld interface and at the sheet external surfaces immediately beneath the teeth. A further factor that needs to be considered is that as the weld 
develops there is a tendency for the tips to be displaced, relative to each other, leading to a net shear imposed across the joint parallel to the sheets. This is not that surprising as the reeds are not elastically rigid. Indeed, they are designed to vibrate and under the compressive applied clamping pressure, as the material softens and the whole weld zone starts to plastically deform, they deflect laterally. This behaviour is driven by the unstable situation of having the sonotrode tip ridges aligned directly above each other, when first compressively loaded, when the teeth and troughs on the opposing tips would prefer to mate, and can be clearly seen in Fig. 5e. While this deflection will depend on the knurl pattern on the tips, for knurled tips the same general behaviour would still be expected to occur irrespective of the tip design.

\subsection{Weld formation}

At low energies, or short weld times, bonding occurs first near the edge of the sonotrode tip footprint directly under the sonotrode tip ridges (Figs. 3a and 5a). This probably results from a non-uniform contact pressure under the sonotrode tips, which is greatest near the edge of the flat platens. This higher pressure near the edge of the platens is caused by the elastic deflection of the sheets (which will not be perfectly flat) as the gap between them is closed under the application of the clamping pressure. Further, although the displacement is small the reeds are fixed at one end and the tips thus do not move in a truly linear manner and will oscillate through a slight arc. In conventional lower power USW, bonding is also usually observed to be greatest at the edge of the weld area [23]. Evidence from the fracture surfaces (Fig. 3) and SEM cross-sections (Fig. 5a) confirm that microbonding first occurs in these areas of higher pressure. The ruptured microbonds on the fracture surfaces were aligned with the rolling lines on the sheet surface (Fig. 3a). This strongly indicates that during the initial stages of welding microbonding first occurs where the oxide is broken by abrasion, or galling, of asperities resulting from the micron-scale roughness of the original rolled sheet surfaces $[18,26]$. Break-up and dispersal of the oxide during microbonding has been clearly shown in Fig. 12b-d. The microbonds increase in density spread, and coalesce as the energy input increases [26]. However, some may fracture and reform. The incorporation of metal/oxide flakes into the weld interface was also observed which is probably caused by fracture of partially welded areas during the early stages of welding (Fig. 12a).

By using dissimilar alloy sheets with different copper levels, we have attempted to track the interface position more reliably than is possible from microscopy of etched standard welds, where sensitisation from severe deformation and second phases can confuse the issue. In the dissimilar sheet weld cross-section views in Fig. 6, the general behaviour agrees well with the original similar 6111 welds, shown in Fig. 5. Although, it could be argued the waviness of the interface is slightly less pronounced, because the two materials do not have identical flow characteristics. This work, along with other evidence, such as the fine scale dispersion of the oxide (e.g. Fig. 12d), has shown that the weld interface displacement probably evolves on three length scales.

In the early stages of weld formation, the oxide dispersal in microbonded regions (Fig. 7d) shown in Fig. 12c is indicative of a very fine scale irregular interface displacement with a wavelength of $\sim 5 \mu \mathrm{m}$. It is possible that at this extremely small length scale we are seeing the result of deformation occurring heterogeneously on the scale of microbands, or persistent slip bands, which are channels for dislocation glide within adjoining grains across the weld-line (shown schematically in Fig. 12e). Slip steps and persistent slip bands in low cycle fatigue are known to result in roughness on a free surfaces [34-36]. In particular, surface extrusions and intrusions observed in fatigue are of a similar magnitude to the wavelength and displacement of the oxide observed [34]. Microbonded interface segments also appear to rotate out of plane generating interfacial roughness on a second coarser length scale of $\sim 20 \mu \mathrm{m}$ (highlighted schematically in Fig. 8c). This behaviour could be readily caused by a small net shear between the welding tips, when the majority of deformation is accommodated at the hot and soft partially bonded interface but, as will be discussed further below, also implies the cyclic strain path experienced by material within the weld is complex and dynamically changes during the welding process.

At higher energies more extreme swirl-like interface folds were observed irregularly along the join-line, superimposed on the coarse wave-like displacement, where the two materials have become intercalated (Figs. 7c and 9a). Comparison with the bond line area shown in Fig. 7a, suggests that these features probably develop from microbond regions formed in the earlier stages of welding. Such events may represent an extreme case of the stretching and rotation of microbonds described above, caused by a relative displacement of the two contacting surfaces when they are only locally bonded. However, overall the above observations of the oxide displacement, microbond rotation and intercalation, or folding, imply that a given local volume element does not experience a simple conservative cyclic strain path. In USW the macroscopic cyclic strain amplitude will dynamically change as the weld develops and there is complex coupling of the sonotrode tips with the sheets, accompanied by acoustic feedback from the parts. Further, the macroscopic displacement of the tips is not necessarily homogeneously accommodated by a simple closed loop strain path on the local scale at the weld interface; i.e. the plastic strain can be accommodated in different regions of the joint area in forward and reverse parts of the displacement cycles, depending on where the material/bonding is weakest. Thus, locally strain 'ratcheting' of microbonded areas is highly likely to occur and this would readily lead to the complex interface folds, or swirl patterns, observed.

At the coarsest length scale the weld-line was seen to displace in a macroscopic wave-like pattern, which was related to the pitch of the teeth $(\sim 0.9 \mathrm{~mm})$. This large scale displacement of the interface only occurred once the temperature in the weld zone rose sufficiently for the material to soften, to such a degree, that the knurl pattern on the sonotrode tips could sink into the sheet surfaces. This behaviour is caused by the forging action of the ridges combined with a progressive lateral deflection of the sonotrode tips, which displaces the weld interface and is illustrated schematically in Fig. 6d. An associated macroscopic shear pattern develops, as the teeth imbed into the two sheets, which connects between opposing tip ridges at $\sim 45^{\circ}$. Ultimately, if the welding energy continues to increase, as the weld area thins, and the tips penetrate fully into the sheets, the teeth become aligned out of phase and start to mesh (Fig. 5e) whereupon the material between the tips effectively becomes corrugated. As there is a net shear parallel to the weld-line, and at high weld energies the interface wave is compressed by the tips sinking into the sheets, the waves can form crests and, or, have their peaks flattened in the process (Fig. 7c).

Tomography of the weld zones showed that with below optimum weld energies large unbonded areas were still present within the welds, which tended to be associated with the areas between the sonotrode tip ridges where there is a lower local pressure (Fig. 10b). When viewed at a higher resolution by SEM (Fig. 8), at lower welding energies, localised unbonded regions were also found to be present between microwelds in regions where bonding had initiated. This partial bonding results in interface failure and a poor weld strength. High welding energies are thus required to spread the bonded areas across the centre of the weld zone, as well to as reduce the defect density within the already microbonded regions near the weld edge, to ensure a sufficiently strong joint to promote a nugget pullout failure. 
Once bonding has occurred along substantial regions of the weld interface, and it starts to become macroscopically displaced in a wave-like pattern, it is apparent that the accepted mechanism for ultrasonic welding $[18,26]$ would become progressively less effective, as it requires relative motion between the two faying surfaces. This would become increasingly difficult as the accumulative bond area and the macroscopic wave-like displacement of the interface increases. However, the flow behaviour promoted by the forging action of the tips will also stretch the weld interface. For example, the macroscopic wave displacement alone more than doubles the weld interface length with the optimum weld energy $(700 \mathrm{~J})$. This may contribute to the bonding process, all be it in a minor way, in a manner similar to that exploited in roll bonding [37]. Compression of the sheets extends the interface fracturing the oxide film, which exposes clean surfaces, that can then metallurgically bond if intimate contact occurs when the material is relatively soft under high pressure. It is likely that this 'forge bonding' effect, contributes to the latter stages of weld formation where there is a declining relative interface vibrational motion.

Small cracks or unbounded regions were found to persist within the weld at the join-line even at high welding energies (Fig. 11). These defects tend to be associated with the sides of the waves generated by the macroscopic displacement of the interface, which are located between the sonotrode tip ridges. Once the interface is inclined, these flaws will be difficult to completely heal because the displacement from the ultrasonic vibration is largely in the horizontal plane and they will not experience as great a compressive pressure. However, for the optimum welds they were relatively rare, and within a given section the unbonded area was less than $5 \%$ of the total interface line length. In any event, once a sufficient weld-line bond strength has been achieved, the limiting factor in failure is the strength of the material at the edges of the thinned weld region, between the top and bottom surface of each sheet, which will control the resistance to weld nugget pullout.

\subsection{Flow features}

This study has shown that the complex flow features seen in HP-USW, described by other researchers as including ripples and vortices, or swirls and spirals [5,16], probably have several origins. Firstly, there is the contribution from the three length scales of interface displacement described above, which readily leads to a wave-like weld interface. One of the most commonly reported observations is of vortices or swirls $[5,16]$. Such microstructures can be caused by a number of events. For example, the collapse of the crests of the macroscopic interface waves during the forging stage can result in 'swirls' in local regions of the interface. The rotation of microbond areas, noted in Fig. 8d, could also generate swirl-like features. However, the 'swirls' reported probably most commonly arise from the intercalation of the two sheets that occurs due to interface folding at an intermediate length scale. This effect originates from the more extreme deformation and rotation of the initial microbonded areas formed in the early stages of welding and has been attributed here to a strain ratcheting process, arising from a non-conservative cyclic strain path within local regions at the interface. The similarity of such features can be seen by comparing the optical image from a dissimilar alloy weld to the SEM-SE images of an electropolished conventional 6111 weld in Fig. 9.

As well as the presence of swirls, bifurcation of the weld-line has been noted in HP-USW. Again, there are several causes of this effect. The most obvious is from the compression of the 'swirls' or waves caused by rotation of microbonded areas (Fig. 8d; stage 3 ) and the more extreme interface folding behaviour noted above. A final special case of weld-line bifurcation is illustrated in Fig. 14. This feature is associated with the fold defect commonly observed at the edge of the weld (Fig. 7d) and is caused by folding in of the sheet

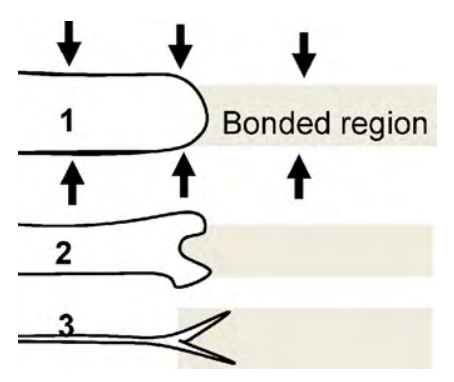

Fig. 14. Schematic diagram of the formation of a ' $y$ ' shaped interface fold at the edge of a bonded area due to compression normal to the weld-line.

surface under compressive displacement at the edge of a bonded region.

\section{Conclusions}

High power ultrasonic spot welding (HP-USW) is a promising, energy-efficient, alternative solid-state joining technique, for welding thin aluminium sheet, closure-panels, in automotive applications. It has been shown that high quality welds possessing, high strength could be produced with extremely short $(\sim 0.3 \mathrm{~s})$ weld times. The mechanical properties of the welds are very good with shear strengths up to $3.5 \mathrm{kN}$ recorded. Strong welds are only produced once a critical threshold welding energy is exceeded, which results in failure by weld pullout. At these weld energies the temperatures in the weld zone reached $>380^{\circ} \mathrm{C}$.

Weld development first involves the development of microwelds at the contact surfaces initiating at the edge of the sonotrode tips, where there is the greatest pressure, before spreading across the weld interface. However, strong welds are only produced when the material becomes softened enough, from the increasing temperature, for plastic deformation to occur throughout the weld zone and there is a considerable forging effect of the sonotrode tips.

By using alloys with dissimilar copper contents, and studying the interfacial oxide, we have attempted to track the interface position more reliably than previously. This has shown that a wavelike displacement of the weld interface probably evolves on three length scales. In the early stages of weld formation, oxide dispersal in microbonded regions is indicative of a very fine scale irregular interface displacement with a wavelength of $\sim 5 \mu \mathrm{m}$. At an intermediate scale $(\sim 20-50 \mu \mathrm{m})$, once formed, microbonded areas appear to rotate out of plane and develop folds or 'swirls', and at the coarsest length scale $(\sim 1 \mathrm{~mm})$, the weld-line was seen to displace in a regular wave-like pattern related to the pitch of the sonotrode tip teeth. This latter behaviour is related to the indentation of the sonotrode tip knurl pattern into the sheet surfaces and the deflection of the sonotrode tips, driven by their desire to mesh, during the forging stage, which generates a net shear displacement.

At low weld energies large unbonded areas were still present within the weld, concentrated at the centre and tended to be associated with the areas between the sonotrode tip ridges where there is a lower local pressure. Small cracks, or unbounded regions, were also found to persist within the weld at the join-line at high welding energies. However, within a given section the unbonded area was less than $5 \%$ of the total interface line length. EBSD analysis of the optimised welds revealed that HP-USW generates a severely deformed interface region, an intermediate shear zone and a surface forged zone. Deformation occurred throughout the weld area generating a microstructure consisting of a recovered substructure with regions containing ultrafine grains within shear bands and near the weld interface.

The complex flow features, described previously by other researchers in HP-USW, were found to have several origins. Firstly, 
the three length scales of displacement readily lead to a wave-like weld interface, when observed at different magnifications. Vortices, or swirls, can be caused by the collapse of the crests of the macroscopic interface waves and the rotation of microbond areas during the forging stage. However, the 'swirls' previously reported probably most commonly arise from the intercalation of the two sheets that occurs due to interface folding, which originates from the initial microbonded areas formed in the early stages of welding. These features are probably caused by material at the join-line locally experiencing a complex dynamically changing, non-conservative, cyclic strain path, which leads to strain ratcheting effects during welding.

\section{Acknowledgements}

The authors would like to thank Dr. Yingchun Chen, Nick Wright and Mike Shergold, for very useful technical discussions, as well as Dimitrios Tsivoula and Dr. Laurent Babout for help with the EBSD and tomographic analysis. We are also grateful to the EPSRC for funding this research through; LATEST2, (EP/G022402/1), and Friction Joining - Low Energy Manufacturing for Hybrid Structures in Fuel Efficient Transport Applications, EP/G022402/1.

\section{References}

[1] C. Lahaye, J. Hisch, D. Bassan, B. Criqui, C. Sahr, in: J. Hirsch, B. Skrozki, G. Gottstein (Eds.), Proceedings of 11th Int. Conf. on Al. Alloys, ICAA11, Aluminium Alloys, Willey-Aachen, VCH, Germany, 2008, pp. 2363-2373.

[2] S. Sakaguchi, J. Light Metal Weld. Const. 17 (3) (1979) 291-297.

[3] J. Peng, S. Fukumoto, L. Brown, N. Zhou, Sci. Technol. Weld. Join 9 (2004) 331-336.

[4] E. Hetrick, R. Jahn, L. Reatherford, Weld. J. 84 (2) (2005) 26.

[5] R. Jahn, R. Cooper, D. Wilkosz, Metall. Mater. Trans. 38A (3) (2007) 570-583.

[6] T.A. Barnes, I.R. Pashby, J. Mater. Proc. Technol. 99 (1-3) (2000) 62-71.

[7] T.A. Barnes, I.R. Pashby, J. Mater. Proc. Technol. 99 (1-3) (2000) 72-79.
[8] B. Harsha, F. Hunt, K. Okamoto, in: R.S. Mishra, M.W. Mahoney (Eds.), Friction Stir Welding Process, ASM, 2007, pp. 235-272.

[9] D. Bakavos, P.B. Prangnell, Sci. Technol. Weld. Join 14 (2009) 443-456.

[10] P. Su, A. Gerlich, T.H. North, G.J. Bendzsak, Sci. Technol. Weld. Join 11 (2004) 163-169.

[11] M. Fukumoto, K. Miyagawa, T. Yasui, M. Tsubaki, Proceedings of 6th Int. Symp. on Friction Stir Welding, Saint-Sauveur, Canada, 10-13 October, TWI, UK Great Abington, 2006, session 13A. Paper 31.

[12] D Mitlin, V. Radmilovic, T. Pan, J. Chen, Z. Feng, M.L. Santella, Mater. Sci. Eng. 441A (1-2) (2006) 76-79.

[13] P.C. Lin, J. Pan, T. Pan, Int. J. Fat. 30 (1) (2008) 90-105.

[14] T. Watanabe, H. Itoh, A. Yanagisawa, M. Hiraishi, Weld. Int. 23 (9) (2009) 633-639.

[15] N.W. Wright, J.D. Robson, P.B. Prangnell, SAE Int. (2009), 01-0027.

[16] S.M. Allameh, C. Mercer, D. Popoola, W.O. Soboyejo, J. Eng. Mater. Technol. (Trans ASME) 127 (1) (2005) 65-74.

[17] E.A. Kenik, R. Jahn, Microsc. Microanal. 9 (suppl. 2) (2003) doi: $10.1017 /$ S1431927603443602.

[18] H.P.C. Daniels, Ultrasonics (1965) 190-196.

[19] S. Elangovan, S. Semeer, K. Prakasan, J. Mater. Proc. Technol. 209 (3) (2009) 1143-1150.

[20] T.H. Hazlett, S.M. Ambekar, Weld. J. 49 (1970) 196s-200s.

[21] X. Cheng, X. Li, J. Micro. Micromech. Microeng. 17 (2007) 273-282.

[22] N. Murdeshwar, J.E. Krzanowski, Metall. Mater. Trans. 28A (1997) 2663-2671.

[23] G.G. Harman, J. Albers, IEEE Trans. PHP13 (1977) 406-412.

[24] I. Lum, J.P. Jung, Y. Zhu, Metall. Mater. Trans. 36A (2005) 1279-1286.

[25] G.D. Blandin, V.A. Kuznetsov, L.L. Silin, Weld. Prod. 10 (1967) 77-80.

[26] J.L. Harthoorn, Doctoral Thesis, De Technische Hogeschool Eindhoven, NL, 1978.

[27] A. Siddiq, E. Ghassemieh, Mech. Solids 40 (2008) 982-1000.

[28] T. Watanabe, H. Itoh, A. Yanagisawam, M. Hiraishi, Weld. Int. 23 (9) (2009) 633-639.

[29] A.C. Kak, M. Slaney, Principles of Computerized Tomographic Imaging, IEEE Press, 1988

[30] P.B. Prangnell, D. Bakavos, Mater. Sci. Forum 638-642 (2010) 1237-1242.

[31] J.R. Davis, Aluminum and Aluminum Alloys, Speciality Handbook, ASM Int., 1993.

[32] P.B. Prangnell, C.P. Heason, Acta Mater. 53 (2005) 3179-3192.

[33] P.B. Prangnell, Y. Huang, M. Berta, P.J. Apps, Mater. Sci. Forum 550 (2007) 159-168.

[34] T.Zhai, J.W. Martin, G.A.D. Briggs, Acta Metall. Mater. 43 (10)(1995)3813-3825

[35] J.-K. Lee, C. Laird, Phil. Mag. A 47 (4) (1983) 579-597.

[36] S. Li, R. Chu, J. Hou, Z. Wang, Phil. Mag. A 77 (4) (1998) 1081-1109.

[37] C.P. Heason, P.B. Prangnell, Mater. Sci. Forum 408-412 (2002) 733-738. 